\title{
Ozone Therapy in integrated cancer management
}

\author{
A. Sreekumar \\ Chairman, Wellness Solutions, Founder Soukhya Foundation, President, Indian Nutritional Medical Association. India.
}

\section{ABSTRACT}

OOPEN ACCESS

\section{Citation}

Sreekumar A. Ozone Therapy in Integrated Cancer Management [abstract]. Proceedings of the 5Th WFOT Meeting; 2016 Nov 18-20; Mumbai, India. J Ozone Ther. 2018;2(2). doi: 10.7203/ jo3t.2.2.2018.11156

\section{Academic Editor}

Jose Baeza-Noci, School of Medicine, Valencia University, SPAIN

\section{Editor}

World Federation of Ozone Therapy, Bolgna, ITALY

\section{Received}

December 9, 2017

\section{Accepted}

December 10, 2017

\section{Published}

March 4, 2018

\section{Intellectual Property}

A. Sreekumar. This is an open access article distributed under the terms of the Creative Commons Attribution License (CC BY 4.0), which permits unrestricted use, distribution, and reproduction in any medium, provided the original author and source are credited.

\section{Author Information}

wellnesssolutions9@gmail.com
Cancer has become one of the most dreadful life style disease causing morbidity \& mortality globally and India is topping the world. But the real fact is "Cancer is one of the most curable diseases in this world today". In 2007 over 12 million new cases were diagnosed across the planet and approximately 7.6 million cancer deaths occurred. By 2050, these numbers will rise to an expected 27 million new cases and 17.5 million cancer deaths if our ability to prevent, diagnose and treat cancer does not improve. Cancer is already the leading cause of death in Canada, Australia, and it's number 2 in Great Britain. In 5 years cancer is expected to be the leading cause of death in USA.

For more than 10 years we at Wellness Solutions have embraced rational cancer therapies proven both effective and minimally damaging to normal tissues and thus we have encouraged synergism between restorative therapies like Nutritional therapy, Ozone therapy and restrained Conventional Cancer therapy. We have found the best results in the combination of Personalized health assessment, Ozone therapy, parenteral nutrients, Oral nutrients \& other Conventional management.

We use simultaneous high dose of Vitamin C, Major Auto Haemo Therapy (MAHT) for more than hundreds of cases with much better results than any modes of conventional \& alternate therapy. High doses of Vitamin C with Ozone therapy have given better results than any chemotherapy protocols. Dr. Otto Warburg (1931 - 1944) proposed the link between Oxygen \& Cancer. Various researches have spent millions of dollars searching for causes of cancer and has reached nowhere. According to Dr. Warburg search for carcinogen is useless without correcting the oxygen deprivation. $60 \%$ deprivation of oxygen in a cell will cause stress leading to disturbance in oxidation/reduction and uncontrolled cell division. We have experiences in more than 100 cancer cases in the last two years.

So, in integrated approach for cancer management Ozone therapy has a very prominent and decisive role for the maintenance of high quality of health \& life. 